\title{
Ovarian teratoma: yet another cause of immune thrombocytopenia
}

This article was published in the following Dove Press journal:

International Journal of Women's Health

\author{
Dalia Khalife' \\ Joseph Nassif' \\ Ali Khalil' \\ Ghina Ghazeeri' \\ Ali Taher ${ }^{2}$
}

'Department of Obstetrics and Gynecology, American University of Beirut Medical Center, Beirut, Lebanon; ${ }^{2}$ Department of Internal Medicine, American University of Beirut Medical Center, Beirut, Lebanon
Correspondence: Ali Taher Division of Hematology-Oncology, Department of Internal Medicine, American University of Beirut Medical Center, PO Box I I-0236, Beirut II 07 2020, Lebanon

Email ataher@aub.edu.lb

\begin{abstract}
A hematologic disorder occurred simultaneously with an ovarian cystic teratoma in a young woman. The blood disorder was a severe thrombocytopenia, with no spontaneous remission, or improvement after steroids tapering. To date, this is the second report in literature of immune thrombocytopenia associated with an ovarian teratoma, completely resolving following surgical excision of the ovarian teratoma. This case may suggest a potential peptide secreted by the ovarian teratoma toxic to platelets, and or a genetic predisposition in patients displaying the syndrome. Further research is needed in this area to highlight the mechanism of association.
\end{abstract}

Keywords: mature ovarian teratoma, immune thrombocytopenia purpura, laparoscopic surgery

\section{Introduction}

Immune thrombocytopenia (ITP) is a hematologic disorder involving accelerated platelet destruction with compromised platelet production, ${ }^{1}$ and defined as a platelet count of $<100,000 / \mu \mathrm{L} .{ }^{2}$ It is divided into primary ITP, an isolated thrombocytopenia, and secondary ITP, where disorders such as infectious (eg, Hepatitis C virus, HIV), or autoimmune (eg, systemic lupus erythematosus, chronic lymphocytic leukemia, antiphospholipid syndrome) disorders are causing the thrombocytopenia. ${ }^{1}$ The incidence of all types of ITP is higher among women $(4.5$ per 100,000) than men (3.2 per 100,000), and is higher at older ages due to the fact that immunological disorder significantly found in the elderly. ${ }^{3}$ It is ultimately a diagnosis by exclusion, made upon assessment of the patients' response to treatment. Purpura at the time of diagnosis is not necessary. Multiple treatments are available. Corticosteroids, intravenous immunoglobulin, and anti-Rho(D) immune globulin are first-line therapies. Second-line therapies include thrombopoietin receptor agonists, rituximab, and splenectomy. ${ }^{4}$

A clinical response is achieved within a week of starting prednisone therapy and maintained over the subsequent months.

Hematologic abnormalities such as thrombocytopenia being associated with gonadal teratomas are very rare. To date, one case was reported in literature of ITP associated with an ovarian teratoma. ${ }^{5}$ The mechanism of association is still intriguing.

We herein describe a case of an unexpected finding of ITP that resolved following surgical excision of a mature cystic teratoma of the ovary in a young woman.

\section{Case report}

Our patient was a 26-year-old nulligravid patient who presented for a regular gynecologic checkup and was found to have a $10 \mathrm{~cm}$ ovarian mass on left ovary, 
suspicious for a mature cystic teratoma. A laparoscopic left ovarian cystectomy was abandoned because the preoperative workup showed a platelet count of $17,000 / \mu \mathrm{L}$.

Her medical history was significant for iron deficiency anemia. She is nonsmoker and nonalcoholic. On consultation with the hematologist, the diagnosis of ITP was made. Three weeks later, she presented to the emergency room at our center with dizziness, occipital headache, and blood-tinged saliva. On examination, she was tachycardic with a heart rate of 113/min, and she had a blood pressure of 109/77 mmHg. Cardiovascular, respiratory, and central nervous system examinations were normal. She had few dispersed lower extremities petechiae. Abdominal examination was diffusely tender on palpation. Complete blood count showed a white blood cell count of $11,700 / \mathrm{L}$ ( $80 \%$ polymorphonuclears), a hemoglobin of $10.3 \mathrm{~g} / \mathrm{dL}$ (hematocrit $32 \%$ ), and a platelet count of $28,000 / \mu \mathrm{L}$. Urine analysis showed positive leukocyte esterase with negative nitrite, rare red blood cells, and subsequently negative culture. Computed tomography scan of brain did not show any intracranial hemorrhage. Infectious workup including, HIV 1 and 2 antibodies, Hepatitis B antigen, anti-HBc, and influenza $\mathrm{A}$ and $\mathrm{B}$, were all negative. Immunological workup including ANA, anti-Smith antibodies, and anti-DsDNA antibodies were negative, in addition to a normal LDH and haptoglobin. Direct antiglobulin test was positive. Peripheral blood smear showed normal morphology of red blood cells and leukocytes, as well as thrombocytopenia with large and giant platelets.

A urea breath test for detection of Helicobacter pylori was nonsignificant. ITP was considered the most likely diagnosis, and the patient was started on prednisone $1 \mathrm{mg} / \mathrm{kg}$.
Following steroid treatment, the platelet count increased to reach $65,000 / \mu \mathrm{L}$. However, it dropped again to $37,000 / \mu \mathrm{L}$ on the next day, along with a drop in hematocrit to $22 \%$. The patient at this point was complaining of diffuse abdominal pain. On abdominal ultrasound and computed tomography scan, the liver, gallbladder, kidneys, spleen, and pancreas were all within normal range. There was moderate volume of ascites in Morison's pouch suggestive of hemoperitoneum with a heterogeneous ill-defined fat lesion containing soft tissue and a calcified structure measuring $9.1 \times 7.3 \mathrm{~cm}$ arising from the left adnexa, in keeping with the ovarian teratoma and a right ovarian hemorrhagic corpus luteum cyst. The drop in hemoglobin was hypothesized to be related to a ruptured corpus luteum cyst in view of the thrombocytopenia risk-related bleeding. She received 2 units of packed red blood cells and was discharged home on prednisone $1 \mathrm{mg} / \mathrm{kg}$ (60 mg daily). Platelets reached 235,000/ $\mathrm{L}$, but dropped to reach $100,000 / \mu \mathrm{L}$ following steroid tapering. The patient underwent a laparoscopic left ovarian cystectomy because of the increase in her abdominal discomfort despite a platelet count of $52,000 / \mu \mathrm{L}$. A $12 \times 5 \times 3 \mathrm{~cm}$ cyst, filled with sebaceous material and hair, was removed with no solid component. The surgery was uneventful. Histological examination confirmed a benign cystic teratoma. The patient was discharged home the following day on steroid tapering. Her platelet count reached $300,000 / \mu \mathrm{L}$ and $390,000 / \mu \mathrm{L}$ on postoperative days 6 and 15, respectively, with normalization of her hematocrit to $41 \%$ (Figure 1). Written informed consent has been provided by the patient for publication of the case details. Institutional approval was not required to publish this case report.

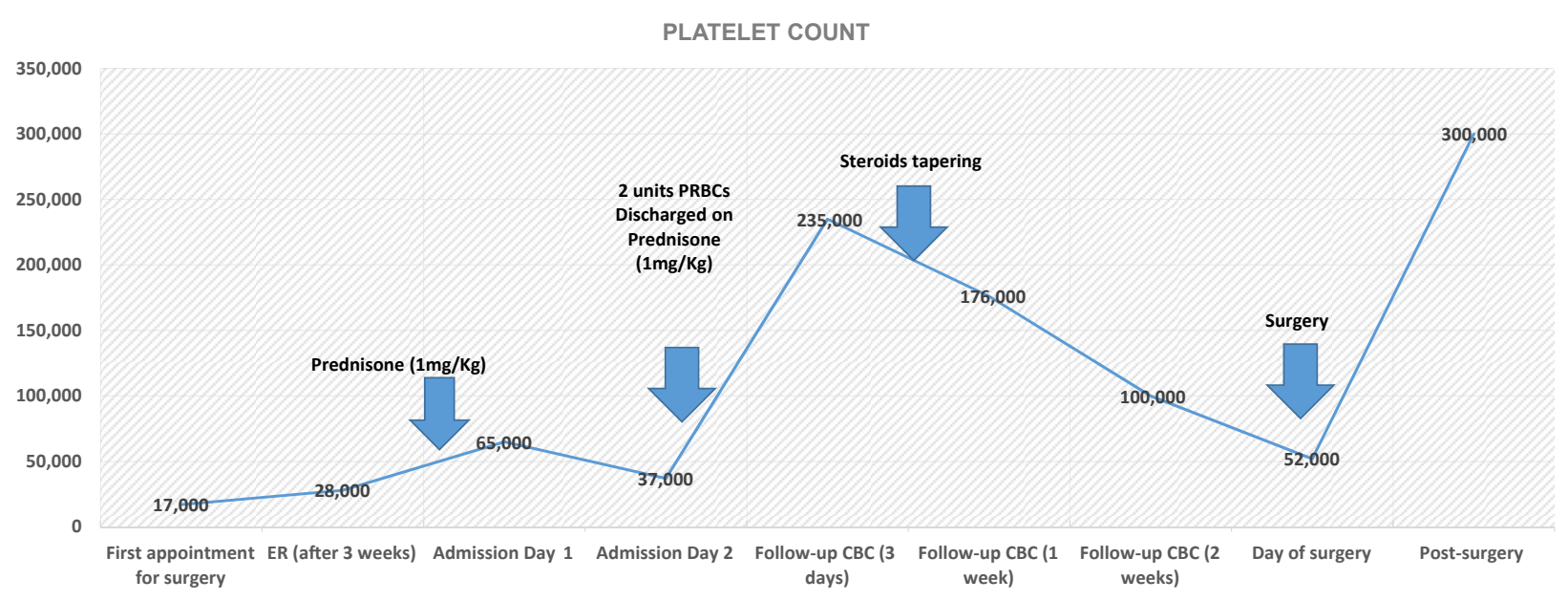

Figure I Platelet count over time and response to treatment.

Abbreviations: $C B C$, complete blood count; ER, emergency room; RBC, red blood cell; PRBCs, packed red blood cells. 


\section{Discussion}

Very limited data are available in the literature regarding the frequency of occurrence, the mechanisms of association, and the clinical behavior of hematologic abnormalities in patients with ovarian teratoma. There is one case of ITP in association with ovarian teratoma described in the literature and was concomitant with pregnancy. ${ }^{5}$ The characteristics of this case and our case are presented in Table 1. Other cases of ITP were described with extragonadal germ cell tumors where all had embryonal cancers with mediastinal masses. ${ }^{6,7}$ The diagnosis of primary ITP was made after a complete workup with normal peripheral blood smear and absence of schistocytes. ITP was persistent for 3 months, since she did not achieve spontaneous remission or complete response after tapering the steroids. Our patient showed symptoms of lower limb petechiae on her second hospital admission.

The mechanism of association between ITP and ovarian teratoma is still unknown. Upon preoperative workup, severe thrombocytopenia was suspected in the current patient. She was responding to the conventional management with steroids; however, her platelets count dropped upon tapering. It is believed that ITP starts with antibodies against a platelet glycoprotein leading to the degradation of antibody-coated platelets in the spleen. This degradation results in the release of more peptides from the platelet constituents, with production of new antibodies against the platelet-derived peptides. ${ }^{1}$ Therefore, we hypothesize that the presence of ovarian teratoma is the specific precipitant to the development of ITP, which then triggers the continuous production of a substance exacerbating an immune function disorder. Since the platelet numbers increased to normal levels 6 days postoperatively, it is unlikely for thrombocytopenia to be antibody mediated. The substance secreted by the teratoma may be toxic to the normal platelets with direct platelet membrane damage, affecting the survival of the platelets. It is likely that the effect is not only on platelet destruction but also on platelet production. If the effect is on platelet production, then the use of thrombopoietin receptor agonists might be of use to increase platelet count prior to surgery in such patients.

This phenomenon explains the relapse of the patient upon steroids tapering. The improvement of thrombocytopenia after surgical excision of the teratoma further supports such a theory.

The time interval from diagnosis of ovarian teratoma to the occurrence of thrombocytopenia is unknown since our patient had the teratoma diagnosis made on regular checkup. The median time interval has been reported to range between 0 and 122 months from the diagnosis of germ cell tumor located in the mediastinum to the manifestation of hematologic disorder. ${ }^{8}$

Table I Characteristics of the two case reports

\begin{tabular}{|c|c|c|}
\hline Characteristics & Soma-Pillay et al, ${ }^{5} 2009$ & Our case \\
\hline Presentation & $\begin{array}{l}\text { 26-year-old, pregnant at } 18 \text { weeks of gestation } \\
\text { Exam: } 10 \times 10 \mathrm{~cm} \text { right tender mass }\end{array}$ & $\begin{array}{l}\text { 26-year-old, single } \\
\text { Incidental finding of a } 10 \mathrm{~cm} \text { left ovarian mass }\end{array}$ \\
\hline Past medical history & Negative & Iron deficiency anemia \\
\hline Signs of bleeding disorder & Few scattered ecchymosis lower limbs & Lower extremities petechiae 3 weeks after diagnosis of ITP \\
\hline Radiology findings & $\begin{array}{l}\text { Pelvic ultrasound: right ovarian } 14 \times 12 \times 12 \text { cystic } \\
\text { echogenic mass with calcification suggestive of ovarian } \\
\text { teratoma }\end{array}$ & $\begin{array}{l}\text { Pelvic CT scan: ill-defined fat lesion containing soft tissue } \\
\text { and a calcified structure } 9.1 \times 7.3 \mathrm{~cm} \text { arising from the left } \\
\text { adnexa, suggestive of ovarian teratoma }\end{array}$ \\
\hline $\begin{array}{l}\text { Initial laboratory } \\
\text { assessments }\end{array}$ & $\begin{array}{l}\text { Hemoglobin: } 9.8 \mathrm{~g} / \mathrm{dL} \\
\text { Platelet: } 4,000 / \mu \mathrm{L} \\
\text { Blood film: large platelets } \\
\text { Malaria, syphilis, and HIV negative } \\
\text { BM biopsy negative }\end{array}$ & $\begin{array}{l}\text { Platelet count initially of } 17,000 / \mu \mathrm{L} \rightarrow \text { surgery deferred } \\
\text { Infectious and immunological workup normal }\end{array}$ \\
\hline Management & $\begin{array}{l}\text { Prednisone I } \mathrm{mg} / \mathrm{kg} \rightarrow \text { platelet remained at } 3,000 / \mu \mathrm{L} \text {. } \\
\text { No response after I week } \\
\text { Intravenous immunoglobulin } \rightarrow \text { platelet increased to } \\
21,000 / \mu \mathrm{L} \text { after } 48 \text { hours }\end{array}$ & $\begin{array}{l}\text { Prednisone }(\mathrm{I} \mathrm{mg} / \mathrm{kg}) \rightarrow \text { platelet reached } 235,000 / \mu \mathrm{L} \\
\text { Prednisone tapering } \rightarrow \text { platelet dropped to } 100,000 / \mu \mathrm{L} \\
(\text { Figure I) }\end{array}$ \\
\hline Treatment & $\begin{array}{l}\text { Open oophorectomy at } 27 \text { weeks } \\
\text { Histology: benign cystic teratoma }\end{array}$ & $\begin{array}{l}\text { Laparoscopic left ovarian cystectomy } \\
\text { Histology: benign cystic teratoma }\end{array}$ \\
\hline Postoperatively & $\begin{array}{l}\text { Day I: platelet increased to } 58,000 / \mu \mathrm{L} \\
\text { After } 2 \text { weeks: } 287,000 / \mu \mathrm{L} \\
\text { Delivery at } 33 \text { weeks for preterm labor }\end{array}$ & $\begin{array}{l}\text { Day 0: platelet } 52,000 / \mu \mathrm{L} \\
\text { Day 6: } 300,000 / \mu \mathrm{L} \\
\text { Day I5: } 390,000 / \mu \mathrm{L}\end{array}$ \\
\hline
\end{tabular}

Abbreviations: BM, bone marrow; CT, computed tomography; ITP, immune thrombocytopenia. 
Thrombocytopenia was the hematologic disorder found in association with the ovarian teratoma. ${ }^{5}$ Nevertheless other hematologic abnormalities that can be seen may include myelodysplasia, idiopathic thrombocytosis, acute lymphocytic leukemia, or acute myeloid leukemia. ${ }^{6-8}$

Patients usually have very poor prognosis; ${ }^{9}$ however, in patients with isolated platelet disorder, prognosis is satisfactory, ${ }^{7}$ as seen in the case of our patient who had a spontaneous remission of the platelet count after the excision of the ovarian teratoma.

Even though the incidence of ITP is higher in older patients (over 60 years), it is not uncommon to diagnose ITP in young patients. Genetic predisposition seems unlikely since ITP was resolved after excision of the teratoma. ${ }^{10}$

The decision to proceed with surgery was taken jointly by a multidisciplinary team involving gynecologists, anesthesiologists, and hematologists. Her platelet count on the day of surgery was 52,000, which is the minimal threshold needed in case of a minor surgery. Hence, no medical health risks were undertaken with the decision to proceed with surgery.

\section{Conclusion}

In conclusion, we present an interesting case of ITP associated with an ovarian teratoma, resolving after its excision. To the best of our knowledge, this is the second case of ITP associated with ovarian cystic teratoma, and it is the first in a nonpregnant woman. No biological explanation has yet been identified; thus, it remains unclear why some patients develop hematologic abnormalities in association with ovarian teratoma. Additional patients displaying these two disorders simultaneously are needed for a better understanding of this association. Despite its rarity, preoperative thrombocytopenia should be excluded in patients with ovarian teratoma.

\section{Disclosure}

Professor Ali Taher report grants from Novartis Pharmaceuticals, Celgene, La Jolla Pharmaceuticals, Ionis Pharmaceuticals, and Protagonist Therapeutics, outside the submitted work. The authors report no other conflicts of interest in this work.

\section{References}

1. Mccrae K. Immune thrombocytopenia: no longer 'idiopathic'. Cleve Clin J Med. 2011;78(6):358-373.

2. Stasi R, Amadori S, Osborn J, Newland AC, Provan D. Long-term outcome of otherwise healthy individuals with incidentally discovered borderline thrombocytopenia. PLoS Med. 2006;3(3):e24.

3. Abrahamson PE, Hall SA, Feudjo-Tepie M, Mitrani-Gold FS, Logie J. The incidence of idiopathic thrombocytopenic purpura among adults: a population-based study and literature review. Eur J Haematol. 2009; 83(2):83-89.

4. Neunert C, Lim W, Crowther M, Cohen A, Solberg L, Crowther MA. The American Society of Hematology 2011 evidence-based practice guideline for immune thrombocytopenia. Blood. 2011;117(16):4190-4207.

5. Soma-Pillay P, Macdonald AP, Mnisi E. A rare case of idiopathic thrombocytopenia in association with an ovarian teratoma in pregnancy. Obstet Med. 2009;2(3):126-127.

6. Garnick MB, Griffin JD. Idiopathic thrombocytopenia in association with extragonadal germ cell cancer. Ann Intern Med. 1983;98(6):926-927.

7. Helman LJ, Ozols RF, Longo DL. Thrombocytopenia and extragonadal germ-cell neoplasm. Ann Intern Med. 1984;101(2):280.

8. Nichols CR, Roth BJ, Heerema N, Griep J, Tricot G. Hematologic neoplasia associated with primary mediastinal germ-cell tumors. $N E n g l$ J Med. 1990;322(20):1425-1429.

9. Hartmann JT, Nichols CR, Droz JP, et al. Hematologic disorders associated with primary mediastinal nonseminomatous germ cell tumors. J Natl Cancer Inst. 2000;92(1):54-61.

10. Roark JH, Bussel JB, Cines DB, Siegel DL. Genetic analysis of autoantibodies in idiopathic thrombocytopenic purpura reveals evidence of clonal expansion and somatic mutation. Blood. 2002;100(4):1388-1398.
International Journal of Women's Health

\section{Publish your work in this journal}

The International Journal of Women's Health is an international, peerreviewed open-access journal publishing original research, reports, editorials, reviews and commentaries on all aspects of women's healthcare including gynecology, obstetrics, and breast cancer. The manuscript management system is completely online and includes

\section{Dovepress}

a very quick and fair peer-review system, which is all easy to use. Visit http://www.dovepress.com/testimonials.php to read real quotes from published authors. 